\title{
Suprascapular neuropathy in volleyball players
}

\author{
E Witvrouw, A Cools, R Lysens, D Cambier, G Vanderstraeten, J Victor, C Sneyers, \\ $M$ Walravens
}

Department of Rehabilitation Sciences and Physiotherapy, Faculty of Medicine, Ghent

University, Belgium

E Witvrouw

A Cools

D Cambier

G Vanderstraeten

Faculty of Physical

Therapy and

Rehabilitation

Sciences, Catholic

University of Leuven,

Belgium

E Witvrouw

R Lysens

J Victor

C Sneyers

Ninnofse stwg 472,1500

Halle, Belgium

$M$ Walravens

Correspondence to:

Dr E Witvrouw, Department

of Rehabilitation Sciences

and Physiotherapy, Faculty

of Medicine, Ghent

University, De Pintelaan 185 ,

9000 Gent, Belgium

Accepted for publication

22 November 1999

\begin{abstract}
Background-Suprascapular nerve entrapment with isolated paralysis of the infraspinatus muscle is uncommon. However, this pathology has been reported in volleyball players. Despite a lack of scientific evidence, excessive strain on the nerve is often cited as a possible cause of this syndrome. Previous research has shown a close association between shoulder range of motion and strain on the suprascapular nerve. No clinical studies have so far been designed to examine the association between excessive shoulder mobility and the presence of this pathol-
\end{abstract} ogy.

Aim-To study the possible association between the range of motion of the shoulder joint and the presence of suprascapular neuropathy by clinically examining the Belgian male volleyball team with respect to several parameters.

Methods-An electromyographic investigation, a clinical shoulder examination, shoulder range of motion measurements, and an isokinetic concentric peak torque shoulder internal/external rotation strength test were performed in 16 professional players.

Results-The electrodiagnostic study showed a severe suprascapular neuropathy in four players which affected only the infraspinatus muscle. In each of these four players, suprascapular nerve entrapment was present on the dominant side. Except for the hypotrophy of the infraspinatus muscle, no significant differences between the affected and non-affected players were observed on clinical examination. Significant differences between the affected and non-affected players were found for range of motion measurements of external rotation, horizontal flexion and forward flexion, and for flexion of the shoulder girdle (protraction); all were found to be higher in the affected players than the non-affected players.

Conclusions-This study suggests an association between increased range of motion of the shoulder joint and the presence of isolated paralysis of the infraspinatus muscle in volleyball players. However, the small number of patients in this study prevents definite conclusions from being drawn.

(Br F Sports Med 2000;34:174-180)

Keywords: suprascapular neuropathy; infraspinatus muscle; volleyball; shoulder mobility
Shoulder problems have become common in the overhead athlete. It is suggested that these athletes are susceptible to injury and dysfunction because of the repetitious high velocity mechanical stress placed on the shoulder, often at extremes of glenohumeral motion. ${ }^{1}$ Nerve lesions are a relative rarity among these athletes compared with instability problems and rotator cuff and acromioclavicular joint pathology. Shoulder instability, specifically glenohumeral instability, is defined as symptomatic translation of the humeral head on the glenoid during motion. ${ }^{2}$ A review of the literature discloses reports of suprascapular nerve palsy in athletes. ${ }^{3-7}$ The most common lesion occurs at the suprascapular notch, resulting in paralysis of the common trunk of the nerve with supraspinatus and infraspinatus hypotrophy. ${ }^{8}$ This entrapment was first described in 1963 by Koppell and Thompson. ${ }^{9}$ No alternative entrapment site was recognised until 1981 when the first case of spinoglenoid notch entrapment was described by Ganzhorn et al. ${ }^{6}$ Entrapment of the nerve at this site is considered very unusual. However, isolated involvement of the infraspinatus has been reported in volleyball players and pitchers. ${ }^{510}$ Despite this knowledge, the pathogenesis of this entity is not yet completely understood.

The suprascapular nerve is derived from the upper trunk of the brachial plexus, receiving its axons from the fifth and sixth cervical roots. Mestdagh et $a l^{11}$ found, in their study on 20 human cadavers, almost no variation between different subjects in the origin of the suprascapular nerve. The nerve then courses laterally through the posterior triangle of the neck across the scalenus medius muscle, under the trapezius and omohyoideus to enter the supraspinous fossa by obliquely passing through the suprascapular notch. The nerve continues its course laterally in the supraspinatus fossa, where it is in direct contact with the belly of the supraspinatus muscle. On an average of $1 \mathrm{~cm}$ after passing the incisura, the nerve provides motor fibres for the supraspinatus muscle and a sensory fibre to the subacromial bursa and glenohumeral and acromioclavicular joints.

The nerve continues its course by curving around the lateral border of the spine of the scapula, the spinoglenoid notch, to gain entrance to the infraspinatus fossa. This notch is covered by the inferior transverse ligament or spinoglenoid ligament, a narrow fibrous band that forms a separation between the supraspinatus and infraspinatus muscle. The prevalence of this ligament has been reported to range from 50 to $72 \% .^{12}{ }^{13}$ The suprascapular nerve then completes its course at a right angle 
and travels medially to the scapular spine. The nerve is held against the bone by the belly and musculotendinous part of the infraspinatus and provides several successive branches to the belly of the infraspinatus. Mestdagh et $a l^{11}$ have shown that, in contrast with its origin, individual variation in the terminal branches of the suprascapular nerve is possible. Ferretti et $a \bar{l}$ postulated players whose suprascapular nerve divides into three terminal branches instead of into a plexus of motor branches may be susceptible to the injury. When this variant is present, the nerve forms an acute angle as it curves around the lateral edge of the spine of the scapula. It cannot be excluded that this variation may partly explain why some volleyball players become injured and others do not. There are no skin sensory endings for the nerve as it is a motor nerve.

A review of the literature reveals several hypotheses for the pathogenesis of isolated paralysis of the infraspinatus muscle. Trauma, ${ }^{14}{ }^{15}$ strain, ${ }^{716}$ hypertrophy of the spinoglenoid ligament, ${ }^{3}{ }^{17}$ ganglion cysts, ${ }^{18}$ and aberrant splitting of the terminal branches of the nerve ${ }^{5}$ have all been reported as possible causes of suprascapular nerve entrapment. Although most reports appear to support the theory of traction of the nerve as the cause of suprascapular nerve entrapment, so far only a few studies have investigated the correctness of this hypothesis. ${ }^{19}$

Martin et $a l^{20}$ showed in their cadaver study that the magnitude of suprascapular nerve elongation was significantly dependent on extreme arm positions. Their data indicate that extreme motions in the shoulder girdle can cause as much as $25 \%$ local elongation of the suprascapular nerve. These data support dynamic entrapment as a possible cause of suprascapular neuropathy, and suggest that players with large ranges of motion in the shoulder girdle are prone to this injury. However, this hypothetical association between range of motion and the presence of suprascapular neuropathy has, to our knowledge, never been investigated. Therefore it is the purpose of this study to examine a possible association between the range of motion of the shoulder girdle and the presence of suprascapular neuropathy with isolated hypotrophy of the infraspinatus muscle in volleyball players.

\section{Materials and methods}

With the approval of the ethics committee of the university hospital, we tested all the members of the Belgian male volleyball team $(\mathrm{n}=$ 16). Before participation, informed consent was obtained from each subject. Of the 16 tested, 15 were right hand dominant. The subjects were aged from 20 to 35 years with a mean age of 26. Their mean (SD) height was 195 $(10.2) \mathrm{cm}$, and mean (SD) weight $89(6.2) \mathrm{kg}$. All were examined at the University Hospital Pellenberg, Belgium.

ELECTROMYOGRAPHIC (EMG) EVALUATION

To quantify the muscles affected by this neuropathy, needle EMG measurements of all shoulders (dominant and non-dominant) were performed at four different regions of the supraspinatus and infraspinatus muscles. Standard procedures consisting of standardised placement of surface electrodes to monitor the responses on Erb's point stimulation were used to examine the conduction time. ${ }^{19}$ The conduction time from the stimulating electrode to the pick up needle was measured. The EMG evaluation of all the players was performed by the same qualified medical doctor, and the results were not available to the other people involved in the study.

CLINICAL EXAMINATION

A careful history was obtained by the same orthopaedic surgeon for each athlete, to obtain information on previous injuries and present shoulder pain. A detailed physical examination was also performed to acquire detailed information about the posture of the shoulder girdle, possible hypotrophy, signs of impingement or instability, and to determine a possible association between a neuropathy of the infraspinatus muscle and any of the above parameters.

With the athlete in the standing position, the presence of any significant hypotrophy, any deformities, and evidence of discoloration or swelling were looked for in the anterior, posterior, and lateral view.

The physical examination proceeded with a wall push up to evaluate serratus anterior weakness. Abduction and forward flexion was carried out to evaluate any asynchrony and dyskinesia of the scapulothoracic rhythm or glenohumeral movement. The physical examination included the impingement tests described by Hawkins and Kennedy ${ }^{21}$ and Neer. ${ }^{22}$

The instability assessment began with the load and shift examination. As the head of the humerus was loaded, both anterior and posterior stresses were applied, and the amount of translation was noted in relation to the glenoid rim. As prescribed by Hawkins and Bokor, ${ }^{23}$ the amount of translation was classified according to three types: type 1 , normal translation or head translates to the rim of the glenoid; type 2 , head translates over the rim; type 3, the head locks out over the rim. For inferior instability, the sulcus sign test was used. If the translation occurs inferiorly, a visual sulcus sign appears which is classified as inferior instability. The next phase of stability assessment was to attempt reproduction of instability symptoms by the apprehension test. ${ }^{24}$ This test was positive if apprehension of the patient to the manoeuvre was provoked. It was carried out with the subject in the supine position to obtain maximum muscle relaxation. It is generally accepted as a valid method of assessing shoulder instability. ${ }^{2024}$

\section{RANGE OF MOTION MEASUREMENTS}

To obtain quantitative information about the mobility of the shoulder girdle and a possible left to right difference, the range of motion was measured bilaterally, and assessed by standard goniometric measurement. ${ }^{25}$ In addition, these measurements can be used to investigate the 
relation between shoulder mobility and the presence of infraspinatus muscle neuropathy.

Active and passive external rotation was assessed with the shoulder in $0^{\circ}, 30^{\circ}$, and $90^{\circ}$ of abduction while the subject was in a supine position. The active and passive internal rotation was examined in the same supine position with the shoulder in $90^{\circ}$ of abduction. The amount of forward flexion of the shoulder was also assessed with the subject in this supine position. To measure backward extension of the shoulder, the subjects were placed in a prone position on the examiner's table. This movement and the forward flexion were both measured bilaterally in order to minimise compensation.

Horizontal flexion was measured with the subject sitting on a stool to allow the scapula to move freely along the thorax.

To measure the lateral displacement of the scapula, the flexion and extension of the shoulder girdle (protraction and retraction) was evaluated. The subject was sitting on a stool and was asked to perform a maximal extension of the shoulder girdle (retraction). In this position the horizontal distance (in $\mathrm{cm}$ ) was measured between the spinous process and the angulus inferior of the medial border of the scapula. Subsequently the subject was asked to flex the shoulder girdle maximally (protraction), and the same measurement was repeated.

As many studies of joint measurements have shown that intratester reliability is higher than intertester reliability, in this study the same examiner, who was experienced with these measurements, performed all range of motion evaluations. All measurements were performed according to the guidelines of the AAOS. ${ }^{25}$ Riddle $e t a l^{26}$ have shown that shoulder range of motion measurements with a universal goniometer, as used in this study, is highly reliable. They found, in their study on 50 patients, intraclass correlation coefficient values for these measurements ranging from 0.94 to 0.98 . This was confirmed by others, ${ }^{27}{ }^{28}$ and also by our own reliability study of the lateral displacement measurement of the scapula, a measurement also used in this study. ${ }^{29}$ In this study, ${ }^{29}$ the intraclass correlation coefficient for intratester reliability of this measurement ranged between 0.96 and 0.8 (for 17 healthy subjects), whereas for intertester reliability it was in the range $0.42-0.9$.

It can be questioned whether goniometric measurements represent real joint or bony motions. However, on the basis of the proven validity of goniometric measurements in the knee and hip joint, ${ }^{30-32}$ one can expect that goniometric measurements of the shoulder joint will also be valid. ${ }^{33}$

ISOKINETIC CONCENTRIC STRENGTH ASSESSMENT To provide us with quantitative and accurate data of muscle strength and left to right differences, bilateral isokinetic concentric peak torque strength was measured by the same qualified person, who was familiar with a Cybex 350 isokinetic dynamometer. Concentric shoulder external/internal peak torque was measured at $60 \%$ s and $180 \%$ s. Subjects were positioned and secured by Velcro strapping according to the Cybex testing manual (Cybex I: Isolated joint testing and exercise; Ronkonkoma, New York, 1983). With regard to the reliability of testing, Kuhlmann et $a \beta^{34}$ showed high reliability of external rotational isokinetic concentric peak torque measurements at $90 \%$ and $210 \%$ on 21 volunteers with no history of shoulder pathology. This is in agreement with the results of Greenfield et al, ${ }^{35}$ who found intratester correlation coefficients of 0.94 to 0.92 for external and internal rotational isokinetic concentric peak torque testing at $60 \%$ s on 20 healthy volunteers.

\section{STATISTICAL ANALYSIS}

Means (SD) were calculated for the different characteristics. Given the small sample size and the fact that the data are not normally distributed, Mann-Whitney U tests were performed to compare the continuous variables between the players who did and did not have suprascapular neuropathy when there was a normal distribution. A non-parametric Wilcoxon test was performed if the distribution did not meet the criterion of normality. This was the case for the active range of motion measurements of $(a)$ external rotation with the arm in $0^{\circ}$ of abduction on the dominant and non-dominant side, $(b)$ external rotation with the arm in $30^{\circ}$ of abduction on the dominant side, $(c)$ internal rotation with the arm in $0^{\circ}$ of abduction on the dominant and non-dominant side, (d) flexion (protraction) on the dominant and non-dominant side, (e) extension (retraction) on the dominant side.

A $\chi^{2}$ or Fisher exact test was used to compare the two groups for the discrete variables. Significance was accepted at the 0.05 level.

\section{Results}

EMG MEASUREMENTS

The electrodiagnostic studies disclosed four cases of isolated denervation in the infraspinatus muscle in the dominant shoulder. These four players showed a complete motor drop out of the infraspinatus muscle on full voluntary effort and at rest. We were unable to show any electrical activity in this muscle in these subjects. No abnormalities were found in the supraspinatus muscle of these four players.

EMG nerve conduction velocities showed complete denervation of the right (dominant) infraspinatus muscle in the four subjects with complete denervation of the infraspinatus muscle. No abnormalities were found in the supraspinatus muscle of these four players.

Table 1 displays anthropometric variables of affected and non-affected players.

Table 1 Mean (X), standard deviations (SD) and minimum and maximum values for height and weight of affected and non-affected players

\begin{tabular}{|c|c|c|c|c|c|c|c|c|}
\hline & \multicolumn{4}{|c|}{$\begin{array}{l}\text { Affected players } \\
(n=4)\end{array}$} & \multicolumn{4}{|c|}{$\begin{array}{l}\text { Non-affected players } \\
(n=12)\end{array}$} \\
\hline & $X$ & $S D$ & min & $\max$ & $X$ & $S D$ & $\min$ & $\overline{\max }$ \\
\hline Height $(\mathrm{cm})$ & 194 & 8.6 & 189 & 199 & 195 & 11.1 & 184 & 202 \\
\hline Weight (kg) & 87 & 4.08 & 84 & 93 & 89 & 6.91 & 181 & 107 \\
\hline
\end{tabular}


Table 2 Mean (X), standard deviations (SD) and minimum and maximum values for the passive range of motion measurements of both groups

\begin{tabular}{|c|c|c|c|c|c|c|c|c|c|}
\hline & \multicolumn{4}{|c|}{ Affected players $(n=4)$} & \multicolumn{4}{|c|}{ Non-affected players $(n=12)$} & \multirow[b]{2}{*}{$p$ Value } \\
\hline & $X$ & $S D$ & $\min$ & $\max$ & $X$ & $S D$ & $\min$ & $\max$ & \\
\hline \multicolumn{10}{|c|}{ External rotation in $0^{\circ} \mathrm{Abd}$} \\
\hline Dom side & 90 & 10 & 77 & 104 & 87 & 10.1 & 74 & 100 & 0.66 \\
\hline Non-dom side & 104 & 6.0 & 96 & 112 & 85 & 13.8 & 69 & 102 & $0.02^{\star}$ \\
\hline \multicolumn{10}{|c|}{ External rotation in $30^{\circ} \mathrm{Abd}$} \\
\hline Dom side & 86 & 5.6 & 80 & 92 & 100 & 7.7 & 89 & 111 & 0.33 \\
\hline Non-dom side & 115 & 5.9 & 105 & 122 & 100 & 10 & 86 & 114 & $0.01^{\star}$ \\
\hline \multicolumn{10}{|c|}{ External rotation in $90^{\circ} \mathrm{Abd}$} \\
\hline Dom side & 137 & 6.3 & 128 & 145 & 115 & 6.9 & 105 & 123 & $0.001^{\star}$ \\
\hline Non-dom side & 134 & 10.2 & 121 & 147 & 118 & 10 & 104 & 130 & $0.02^{\star}$ \\
\hline \multicolumn{10}{|l|}{ Internal rotation } \\
\hline Dom side & 11 & 5 & 7 & 19 & 19 & 2.5 & 14 & 24 & 0.65 \\
\hline Non-dom side & 9 & 2.1 & 6 & 13 & 10 & 2.8 & 6 & 15 & 0.41 \\
\hline \multicolumn{10}{|l|}{ Horizontal flexion } \\
\hline Dom side & 180 & 15.9 & 162 & 198 & 171 & 21.5 & 146 & 194 & 0.67 \\
\hline Non-dom side & 186 & 10 & 177 & 201 & 173 & 7.9 & 164 & 184 & $0.02^{\star}$ \\
\hline \multicolumn{10}{|l|}{ Forward flexion } \\
\hline Dom side & 211 & 16.6 & 194 & 230 & 196 & 9.1 & 185 & 204 & 0.13 \\
\hline Non-dom side & 207 & 6.4 & 199 & 217 & 194 & 11.1 & 180 & 207 & $0.04^{\star}$ \\
\hline \multicolumn{10}{|l|}{ Backward extension } \\
\hline Dom side & 93 & 4.8 & 88 & 97 & 83 & 24.5 & 56 & 111 & 0.20 \\
\hline Non-dom side & 93 & 3.3 & 88 & 99 & 82 & 25.6 & 68 & 102 & 0.16 \\
\hline
\end{tabular}

All values are presented in degrees, except internal rotation which is expressed in $\mathrm{cm}$. Abd, abduction; dom, dominant.

${ }^{\star}$ Significant at $\mathrm{p}<0.05$.

Table 3 Mean (X), standard deviations (SD) and minimum and maximum values for the active range of motion measurements of both groups

\begin{tabular}{|c|c|c|c|c|c|c|c|c|c|}
\hline & \multicolumn{4}{|c|}{ Affected players $(n=4)$} & \multicolumn{4}{|c|}{ Non-affected players $(n=12)$} & \multirow[b]{2}{*}{$p$ Value } \\
\hline & $X$ & $S D$ & $\min$ & $\max$ & $X$ & $S D$ & $\min$ & $\max$ & \\
\hline \multicolumn{10}{|c|}{ External rotation in $0^{\circ} \mathrm{Abd}$} \\
\hline Dom side & 58 & 7.2 & 50 & 67 & 69 & 7.9 & 59 & 74 & 0.40 \\
\hline Non-dom side & 75 & 6.6 & 68 & 85 & 64 & 9.5 & 52 & 77 & 0.12 \\
\hline \multicolumn{10}{|c|}{ External rotation in $30^{\circ} \mathrm{Abd}$} \\
\hline Dom side & 77 & 8.2 & 70 & 88 & 82 & 7.4 & 73 & 92 & 0.28 \\
\hline Non-dom side & 90 & 10.4 & 78 & 102 & 83 & 9 & 72 & 94 & 0.24 \\
\hline \multicolumn{10}{|c|}{ External rotation in $90^{\circ} \mathrm{Abd}$} \\
\hline Dom side & 97 & 6.6 & 90 & 105 & 97 & 10.8 & 84 & 110 & 0.94 \\
\hline Non-dom side & 108 & 10.6 & 95 & 122 & 93 & 8.5 & 84 & 105 & $0.03^{\star}$ \\
\hline \multicolumn{10}{|l|}{ Internal rotation } \\
\hline Dom side & 11 & 5 & 5 & 18 & 12 & 4.1 & 6 & 17 & 0.60 \\
\hline Non-dom side & 6 & 2.3 & 4 & 9 & 10 & 3.6 & 7 & 15 & 0.54 \\
\hline \multicolumn{10}{|l|}{ Horizontal flexion } \\
\hline Dom side & 157 & 4.1 & 150 & 164 & 153 & 18.1 & 133 & 174 & 0.81 \\
\hline Non-dom side & 163 & 7.6 & 153 & 173 & 158 & 9.3 & 147 & 169 & 0.36 \\
\hline \multicolumn{10}{|l|}{ Forward flexion } \\
\hline Dom side & 199 & 15.7 & 185 & 220 & 183 & 10.2 & 172 & 191 & $0.03^{\star}$ \\
\hline Non-dom side & 199 & 10.6 & 187 & 209 & 182 & 11.9 & 168 & 193 & $0.03^{\star}$ \\
\hline \multicolumn{10}{|c|}{ Backward extension } \\
\hline Dom side & 45 & 6.6 & 38 & 55 & 41 & 17.6 & 22 & 55 & 0.69 \\
\hline Non-dom side & 40 & 10.3 & 31 & 54 & 42 & 21.1 & 23 & 57 & 0.88 \\
\hline
\end{tabular}

All values are presented in degrees, except internal rotation which is expressed in $\mathrm{cm}$. Abd, abduction; dom, dominant.

$\star$ Significant at $\mathrm{p}<0.05$.

Table 4 Mean (X), standard deviations (SD) and minimum and maximum values for the flexion and extension range of motion measurements of the shoulder girdle of both groups

\begin{tabular}{|c|c|c|c|c|c|c|c|c|c|}
\hline & \multicolumn{4}{|c|}{ Affected players $(n=4)$} & \multicolumn{4}{|c|}{ Non-affected players $(n=12)$} & \multirow[b]{2}{*}{$p$ Value } \\
\hline & $X$ & $S D$ & $\min$ & $\max$ & $X$ & $S D$ & $\min$ & $\max$ & \\
\hline \multicolumn{10}{|c|}{ Flexion (protraction) } \\
\hline Dom side & 22 & 1.2 & 17 & 25 & 19 & 1.8 & 16 & 23 & $0.03^{\star}$ \\
\hline Non-dom side & 21 & 1.8 & 18 & 26 & 19 & 1.8 & 15 & 23 & $0.04^{\star}$ \\
\hline \multicolumn{10}{|c|}{ Extension (retraction) } \\
\hline Dom side & 7 & 0.9 & 6 & 10 & 8 & 3.8 & 6 & 14 & 0.8 \\
\hline Non-dom side & 5 & 0.7 & 4 & 8 & 6 & 1 & 5 & 8 & 0.19 \\
\hline
\end{tabular}

All values are presented in $\mathrm{cm}$. Dom, dominant.

$\star$ Significant at $\mathrm{p}<0.05$.

CLINICAL INVESTIGATION

On physical examination, each athlete had normal results for the wall push up, scapulothoracic rhythm, Kennedy test, and sulcus sign. All four affected players showed severe hypotrophy of the infraspinatus muscle on the dominant side. There was no history of significant injury or pain in these four players, and none complained of loss of function or even of reduced efficiency when playing volleyball.

The Neer test was twice positive in the nondominant side of the non-affected players and once in the dominant arm of an affected player. The latter also showed instability of grade II in the anterior direction and positive apprehension on the injured side. Of the non-affected players, one showed a slight positive load and shift test anteriorly and a positive apprehension test. In addition, two unaffected players showed a load and shift test of grade I anteriorly and posteriorly on the nondominant arm and one player on the dominant arm.

\section{RANGE OF MOTION AND LAXITY}

Table 2 gives mean (SD) values for passive range of motion for both groups. Significant differences between the two groups were found on the dominant side for external rotation at $90^{\circ}$ of shoulder abduction $(\mathrm{p}=0.001)$. The affected players showed a significantly greater range of motion for this movement than the non-affected players. For the non-dominant side, a significant difference was found for external rotation at $0^{\circ}, 30^{\circ}$, and $90^{\circ}$ of abduction ( $\mathrm{p}=0.02, \mathrm{p}=0.01$, and $\mathrm{p}=0.02$ respectively), for horizontal flexion ( $p=0.02)$, and for forward flexion $(\mathrm{p}=0.04)$ (table 2). As observed for the dominant side, the affected players showed a greater range of motion than the non-affected players for these measurements.

Table 3 reports the results, after statistical analysis, for the active movements. Significant differences between the two groups were observed on the non-dominant side for external rotation at $90^{\circ}$ of shoulder abduction $(\mathrm{p}=$ $0.03)$ and for forward flexion $(p=0.03)$. For each of these measurements, a significantly greater range of motion was established for the affected players than the non-affected players.

With regard to the active range of motion measurements on the dominant side (table 3), analysis of variance disclosed a significantly greater forward flexion in the affected players than in the non-affected players $(p=0.03)$.

With regard to mobility of the shoulder girdle, the affected players showed significantly greater flexion (protraction) on both the dominant and non-dominant side $(\mathrm{p}=0.03$ and $\mathrm{p}=$ 0.04 respectively) than the unaffected players (table 4). No significant difference was found for the extension (retraction) of the shoulder girdle between the two groups $(p>0.05)$ (table $4)$.

FUNCTIONAL STRENGTH ASSESSMENT

Table 5 shows the isokinetic concentric peak torque characteristics of the internal and external rotation muscles of the dominant and nondominant shoulder of both groups. Significant differences were identified between the affected and non-affected players for internal rotation isokinetic concentric peak torque strength $(p=0.01)$. For this measurement, significantly higher values were obtained for the 
Table 5 Mean peak torque (X), standard deviations (SD) and minimum and maximum values for the isokinetic concentric peak torque data of both groups

\begin{tabular}{|c|c|c|c|c|c|c|c|c|c|}
\hline & \multicolumn{4}{|c|}{ Affected players $(n=4)$} & \multicolumn{4}{|c|}{ Non-affected players $(n=12)$} & \multirow[b]{2}{*}{$p$ Value } \\
\hline & $X$ & $S D$ & $\min$ & $\max$ & $X$ & $S D$ & min & $\max$ & \\
\hline \multicolumn{10}{|c|}{ Internal rotation $60 \% \mathrm{~s}$} \\
\hline Dom side & 112 & 23.2 & 73 & 146 & 85 & 13.9 & 48 & 108 & $0.01^{\star}$ \\
\hline Non-dom side & 107 & 30.2 & 65 & 147 & 77 & 10.8 & 43 & 92 & $0.01^{\star}$ \\
\hline \multicolumn{10}{|c|}{ Internal rotation $180^{\circ} / \mathrm{s}$} \\
\hline Dom side & 106 & 22.7 & 77 & 147 & 77 & 14.5 & 49 & 88 & $0.01^{\star}$ \\
\hline Non-dom side & 94 & 13.7 & 62 & 115 & 72 & 12.6 & 53 & 84 & $0.01^{\star}$ \\
\hline \multicolumn{10}{|c|}{ External rotation $60 \% \mathrm{~s}$} \\
\hline Dom side & 50 & 8.8 & 33 & 79 & 57 & 10.9 & 38 & 82 & 0.30 \\
\hline Non-dom side & 66 & 11.6 & 46 & 97 & 52 & 10.8 & 36 & 75 & $0.04^{\star}$ \\
\hline \multicolumn{10}{|c|}{ External rotation $180 \% / \mathrm{s}$} \\
\hline Dom side & 35 & 7.5 & 24 & 47 & 42 & 9.1 & 26 & 55 & 0.21 \\
\hline Non-dom side & 48 & 5.1 & 36 & 62 & 37 & 10 & 31 & 47 & 0.07 \\
\hline
\end{tabular}

All data are expressed in N.m/kg. Dom, dominant.

$\star$ Significant at $\mathrm{p}<0.05$.

Table 6 Mean peak torque (X), standard deviations (SD) and minimum and maximum values for the dominant and non-dominant isokinetic concentric peak torque data of the affected players $(n=4)$

\begin{tabular}{|c|c|c|c|c|c|c|c|c|c|}
\hline & \multicolumn{4}{|c|}{ Dominant side } & \multicolumn{4}{|c|}{ Non-dominant side } & \multirow[b]{2}{*}{ p Value } \\
\hline & $\bar{X}$ & $S D$ & $\min$ & $\max$ & $\bar{X}$ & $S D$ & $\min$ & $\max$ & \\
\hline \multicolumn{10}{|c|}{ Internal rotation } \\
\hline $60 \% \mathrm{~s}$ & 112 & 23.2 & 73 & 146 & 107 & 30.2 & 65 & 147 & 0.32 \\
\hline $180 \% / \mathrm{s}$ & 106 & 22.7 & 77 & 147 & 94 & 13.7 & 62 & 115 & 0.15 \\
\hline \multicolumn{10}{|c|}{ External rotation } \\
\hline $60 \% \mathrm{~s}$ & 50 & 8.8 & 33 & 79 & 66 & 11.6 & 46 & 97 & $0.03^{\star}$ \\
\hline $180 \% \mathrm{~s}$ & 35 & 7.5 & 24 & 47 & 48 & 5.1 & 36 & 62 & $0.03^{\star}$ \\
\hline
\end{tabular}

All data are expressed in N.m/kg.

$\star$ Significant at $\mathrm{p}<0.05$ ball players. ${ }^{710}$ Its incidence $(25 \%)$ in the Belgian male volleyball team in this study compares favourably with values reported by others. ${ }^{7}{ }^{10}$ In our study, no abnormalities were found in the supraspinatus muscle of the four affected players, suggesting that the spinoglenoid notch was probably the site of entrapment. However, because of the small number of patients in this study, one must be very careful in translating these results into percentages.

In this study, none of the affected players complained of pain, loss of function, or even reduced efficiency when they played volleyball. This total absence of symptoms may on first sight be very surprising, but is in accordance with the findings of others. ${ }^{10}{ }^{39}$ Because the nerve has already provided a few sensory filaments for the subacromial bursa before reaching the point of entrapment, the site of involvement could explain the total absence of pain which has allowed the syndrome to go undetected for so long, resulting in complete irreversible denervation of the infraspinatus muscle. Because paralysis of the infraspinatus muscle results in loss of function of a major humeral head depressor and creates a potential imbalance in the force couple formed by the deltoid and the rotator cuff muscles, ${ }^{40}$ we expected to find more secondary shoulder injuries in the affected than the non-affected players. However, this was not the case. Our observations confirm the results of Ferretti et $a l,{ }^{39}$ who found in their follow up study that volleyball players who suffered from this syndrome did not show progressive shoulder dysfunction or any increased incidence of painful overuse syndromes (impingement). However, because of the small number of patients in our study, we were unable to compare the two groups statistically with respect to instability and impingement signs.

Isokinetic concentric peak torque testing disclosed a significant loss in external rotation strength when the affected shoulder was compared with the unaffected side. This finding is in agreement with the results of Ferretti et $a \tilde{l}$ and Ganzhorn et $a l,{ }^{6}$ who both observed an external rotation strength deficit in the affected shoulder.

We observed significantly higher bilateral isokinetic concentric peak torque shoulder strength in the affected players than in the non-affected players for all strength measurements, except for the external rotation strength of the injured side. On the basis of these data, we conclude that the affected players display significantly greater overall isokinetic concentric peak torque shoulder strength than the non-affected players. Therefore the presence of the suprascapular neuropathy is associated with increased overall shoulder strength. However, these results must be interpreted with great caution, as we only measured the strength isokinetically and concentrically and used the peak torque value, so we did not know the players' strength in various angles throughout the range of motion, the eccentric strength, and the force development at higher speeds or during the stretch shortening cycle. The last of scapula. There are some reports of this pathology in the literature..$^{3-51238}$ Despite its rarity, this pathology is sometimes observed in volley- 
these is extremely important to functional performance.

Although this selective hypotrophy of the infraspinatus muscle, together with its symptoms, has been well described,,$^{5-7} 38$ the reason why some players sustain this injury whereas others, with similar amounts of training, do not remains enigmatic. The present study was designed to investigate the pathogenesis of this nerve entrapment. Several mechanisms have been proposed to explain the progressive, and potentially irreversible, changes in the infraspinatus muscle. Most studies ${ }^{516}$ describe traction, or stretching of the nerve, as the most plausible pathomechanism. This traction injury may occur when repetitive overhead activities result in local nerve strain that exceeds the passive tolerance of the nerve. Martin et $a l^{0}$ found that the magnitude of elongation of the suprascapularis nerve was significantly dependent on the rotation of the scapula. Furthermore, they showed that extreme arm positions result in large rotations of the scapula. They therefore concluded that extreme shoulder positions may cause increased strain and subsequent ischaemia, irritation, and swelling of the nerve. In addition, Sandow and $\mathrm{Ilic}^{41}$ showed that extreme shoulder abduction with full external rotation places the suprascapular nerve in a vulnerable situation. These extreme shoulder movements are frequently and repetitively performed in all overhead sports activities. The results of the studies of Martin et $a l^{20}$ and Sandow and Ilic ${ }^{41}$ suggest that the greater the shoulder mobility, the more vulnerable the suprascapular nerve is to stretching.

In our study, the players with suprascapular nerve entrapment displayed significantly greater shoulder mobility than those without. These differences in range of motion were observed in the dominant and non-dominant shoulder joint, and support the stretch theory in the pathogenesis of this syndrome.

We acknowledge several potential limitations of our study. One must bear in mind that the small number of patients limits the interpretation of results. In addition, the mobility was measured clinically. Despite several studies that confirm the reliability of these measurements, the standard errors suggest a need for cautious interpretation of their precision. We recognise that the error inherent in the measurements make strict interpretation of the results unwarranted. In addition, no data are available on their validity. Furthermore, we did not measure directly the magnitude of the elongation of the nerve. On the basis of other studies, ${ }^{20}$ we assume that measuring shoulder mobility can be regarded as an indirect assessment of the amount of stretch of the nerve.

Looking at movements specific to volleyball, the only two asymmetrical and powerful movements typical of the game are the service and smash. In contrast with other authors, ${ }^{42}$ we believe that the service and smash in volleyball are not similar to the shoulder movement in many other overhead sports. In volleyball, the server does not aim for maximum speed, as in pitching, but rather tries to send the ball in a floating trajectory. ${ }^{43}$ To achieve this, the posterior muscles of the shoulder must provide a braking action in the forward movement of the serving arm. Therefore these muscles must be eccentrically activated. This action increases the distance between the points of origin and termination of the nerve, and this may cause tension of the nerve at the lateral edge of the spinoglenoid notch. ${ }^{39}$ The fact that the incidence of this pathology in volleyball players is high suggests that the nature of the game plays an important role in the pathogenesis of this lesion.

As the number of subjects that we examined is limited, we must proceed with caution in interpreting our results. The study can be considered as a pilot study for more extensive investigations into the exact relation between shoulder joint mobility and shoulder muscle strength and the presence of suprascapular neuropathy in volleyball players. Furthermore, on the basis of the results of this study, we cannot exclude the possibility that other causes of suprascapular entrapment suggested in the literature-for example, ganglion cysts-may be involved.

\section{CONCLUSIONS}

In this study the affected players displayed a bilateral greater shoulder isokinetic concentric peak torque strength and shoulder mobility than the unaffected players. This suggests that congenitally greater shoulder mobility, possibly combined with great overall isokinetic concentric peak torque shoulder strength, may place volleyball players at greater risk of developing this pathology. This may be explained by the fact that greater shoulder mobility places the suprascapular nerve in a more likely position to be injured by traction.

It is tempting to ascribe the presence of this pathology to the factors of mobility and isokinetic concentric peak torque strength which are shown in this study to be significantly associated with this injury. However, the small sample size and the retrospective study design limit the possibility of drawing definite conclusions. Further research is required before any conclusions about the relation between this pathology and shoulder muscle strength and mobility can be drawn.

1 Chan K, Liu S, Maffulli N, Nobuhara K, et al. Controversies in orthopaedic sports medicine. Hong Kong: Williams \& Wilkins, 1998

2 Matsen FA, Harryman DT, Sidles JA. Mechanics of glenohumeral instability. Clin Sports Med 1991;10:783-8

3 Aiello IG, Serra CT, Tugnoli V. Entrapment of the Aiello IG, Serra CT, Tugnoli V. Entrapment of the
suprascapular nerve at the spinoglenoid notch. Ann Neurol

4 Black KP, Lombardo JA. Suprascapular nerve injuries with isolated paralysis of the infraspinatus. Am $\mathcal{F}$ Sports Med 1990;18:225-8.

5 Ferretti AG, Cerullo G, Russo G. Suprascapular neuropathy in volleyball players. F Bone foint Surg [Am] 1987;77:1061-

6 Ganzhorn RW, Hocker JT, Horowitz M. Suprascapular nerve entrapment: case report. I Bone foint Surg [Am] 1981;63:492-4

7 Ringel SP, Treifhaft M, Carry M. Suprascapular neuropathy in pitchers. Am F Sports Med 1990;18:80-6. 8 Steiman I. Painless infraspinatus atrophy due to suprascapu-
lar nerve entrapment. Arch Phys Med Rehabil 1988;69:6413.

9 Koppell HP, Thompson WAL. Peripheral entrapment neuropathies. Baltimore: Williams \& Wilkins, 1963. 
10 Holzgraefe M, Kukowski B, Eggert S. Prevalence of latent and manifest suprascapular neuropathy in highperform $177-9$.

11 Mestdagh H, Deinzenkoa D, Ghestem P. Anatomical bases of suprascapular nerve syndrome. Anatomia Clinica 1981;3 $67-71$

12 Kaspi A, Pickmann G. Entrapment of the distal suprascapular nerve. Am $\mathcal{F}$ Sports Med 1990;18:225-8.

13 Demaio M, Drez D, Mullins RC. The inferior transverse scapular ligament as a possible cause of entrapment neuropathy of the nerve to the infraspinatus. F Bone foint Surg [Am] 1991;73:1061-3.

14 Edeland HG, Zarchrisson BE. Fracture of the scapular notch associated with lesion of the suprascapular nerve. Acta Orthop Scand 1975;46:758-63.

15 Kaplan PE, Kernahan WTJ. Rotator cuff rupture: management with suprascapular neuropathy. Arch Phys Med Rehabil 1984:65:273-5.

16 Agre JC, Cameron MC, House J. Suprascapular neuropathy after intensive progressive resistive exercise: case report. after intensive progressive resistive ex
Arch Phys Med Rehabil 1987;68:236-8.

17 Holzgraefe M, Klingelofer J, Eggert S. Zur chronischen Neuropathie des N. Suprascapularis bei Hochleistungssportlern. Der Nervenarzt 1988;59:545-8.

18 Ogino T, Minami A, Kato H. Entrapment neuropathy of the suprascapular nerve by a ganglion. F Bone foint Surg [Am] 1991;73:141-7.

$19 \mathrm{Ma}$ DW, Liveson JA. Nerve conduction handbook. Philadelphia: FA Davis, 1983.

20 Martin SD, Simmons C, Koris M. Suprascapular nerve strain: a biomechanical study. Book of abstracts and outlines. AOSSM 23rd Annual Meeting, Sun Valley, Idaho, 1997:776-8.

21 Hawkins RJ, Kennedy JC. Impingement syndrome in athletes. Am F Sports Med 1980;8:151-7.

22 Neer C. Impingement lesions. Clin Orthop 1983;173:71-7.

23 Hawkins RJ, Bokor DJ. Clinical evaluation of shoulder problem. In: Rockwood CA, Matsen FA, eds. The shoulder. problem. In: Rockwood CA, Matsen FA, eds.

24 Kvitne RS, Jobe FW. The diagnosis and treatment of anterior instability in the throwing athlete. Clin Orthop 1993:291:107-23.

25 American Academy Of Orthopaedic Surgeons. The clinical measurement of joint motion. Chicago: Greene WB, Heckman, 1993

26 Riddle DL, Rothstein JM, Lamb RL. Goniometric reliability in a clinical setting: shoulder measurements. Phys Ther 1987;67:668-73.
27 Gajdosik RL, Bohannon RW. Clinical measurement of range of motion: review of goniometry emphasizing
reliability and validity. Phys Ther 1987;67:1867-70.

28 Boone DC. Reliability of goniometric measurements. Phys Ther 1978;58:1355-8.

29 T'jonck L, Lysens R, Grasse G. Measurements of scapular position and rotation: a reliability study. Physiotherapy Research International 1996;1:148-58.

30 Gogia PP. Reliability and validity of goniometric measurements of the knee. Phys Ther 1987;67:192-5.

31 Enwemka CS. Radiographic verification of knee goniometry. Scand F Rehabil Med 1986;18:47-52.

32 Ahlback SO, Lindahl O. Sagittal mobility of the hip-joint. Acta Orthop Scand 1964:34:310.

33 NorkinCC, White DJ. Measurement of joint motion. In: $a$ guide to goniometry. Philadelphia: FA Davis Company, 1995.

34 Kuhlmann JR, Ianotti JP, Kelly MJ, et al. Isokinetic and isometric measurement of strength of external rotation and metric measurement of strength of external rotation and
abduction of the shoulder. F Bone foint Surg [Am] 1992;74: abduction

35 Greenfield BH, Donatelli R, Wooden MJ, et al. Isokinetic evaluation of shoulder rotational strength between the plane of scapula and the frontal plane. Am $\mathcal{F}$ Sports Med 1990;18:124-8.

36 Zeiss J, Woldenberg LS, Saddemi SR, et al. MRI of suprascapular neuropathy in a weight lifter. $\mathcal{F}$ Comput Assist Tomogr 1993; 17:303-8.

37 Torres-ramos FM, Biundo JJ. Suprascapular neuropathy during progressive resistive exercises in a cardiac rehabilitation program. Arch Phys Med Rehabil 1992;73:1107-11.

38 Bryan WJ, Wild JJ. Isolated infraspinatus atrophy. Am $\mathcal{f}$ Sports Med 1989;17:130-1.

39 Ferretti A, De Carli A, Fontana M. Entrapment of suprascapular nerve at spinoglenoid notch. Book of Abstracts and Outlines. AOSSM 23rd Annual Meeting, Sun Valley, Idaho, 1997:781-2.

40 Warner JP, Micheli LJ, Arslanian LE, et al. Patterns of flexibility, laxity, and strength in normal shoulders and shoulders with instability and impingement. Am $₹$ Sports Med 1990;18:366-75.

41 Sandow MJ, Ilic J. Suprascapular nerve rotator cuff compression syndrome in volleyball players. I Shoulder Elbow Surg 1998;7:516-21.

42 Michaud T. Biomechanics of unilateral overhand throwing motion: an overview. Chiropractic Sports Medicine 1990;4: $13-26$.

43 Neville WJ. Coaching volleyball successfully. Champaign, IL: Human Kinetics, 1990.

Take home message

Volleyball players with increased range of motion of the shoulder girdle appear to be more likely to suffer suprascapular nerve entrapment with isolated paralysis of the infraspinatus muscle. 